\title{
Quality Higher Education: A Need for Sustainable Development
}

\author{
Himanshu Tripathi ${ }^{1 *}$
}

\section{ABSTRACT}

The National Policy on Education was framed in 1986 and modified in 1992. Since then several changes have taken place that calls for a revision of the Policy. In past efforts had already been done for primary and secondary education. It is the Higher Education which is to be looked upon if India wants to grow. A Sustainable Development could not be achieved if Higher Education is neglected at any cost. The Higher Education system in India is complex. With a Gross Enrolment Ratio (GER) of 23 per cent, India is still below the world average. With relatively stagnant growth of public sector, private sector now accounts for 75 per cent of the total Higher Education institutions and 65 per cent of the total enrolments in Indian Higher Education. This paper is a study to find out how three pillars of SD- economy, ecology and society can be interlinked by the Higher Education of a country. Moreover to have a sound Sustainable Development it is necessary to have a quality Higher Education in order to effectively interlink these three areas. This can be achieved if we bring desired changes in the teaching-learning process and in learning environment also. This paper is a study of present condition of Higher Education in India and improvement needed to make a sound Higher Education system to attain SD.

Keywords: SD stands for Sustainable Development, HE stands for Higher Education

Education is not a mere process to comprehend the highest levels of knowledge but a continuous activity that creates new knowledge to sustain life across temporal and spatial barriers. Education is provided at primary, secondary and tertiary level. Since, independence various steps have already been taken place at lower levels. But Higher Education at National and State levels have been neglected.

\section{Higher Education:}

It means university level education which ranges from acquiring Higher National Diplomas and Foundation Degrees to Honours Degrees.

\footnotetext{
${ }^{1}$ Research Scholar (Education), Alagappa University, Karaikudi, Tamil Nadu, India

*Responding Author

(C) 2016 I H Tripathi; licensee IJIP. This is an Open Access Research distributed under the terms of the Creative Commons Attribution License (http://creativecommons.org/licenses/by/2.0), which permits unrestricted use, distribution, and reproduction in any Medium, provided the original work is properly cited.
} 


\title{
Quality Higher Education: A Need for Sustainable Development
}

\section{Sustainability:}

Sustainability about maintaining or sustaining something. In order to sustain something it may well be necessary to integrate its components. Components of sustainability are:

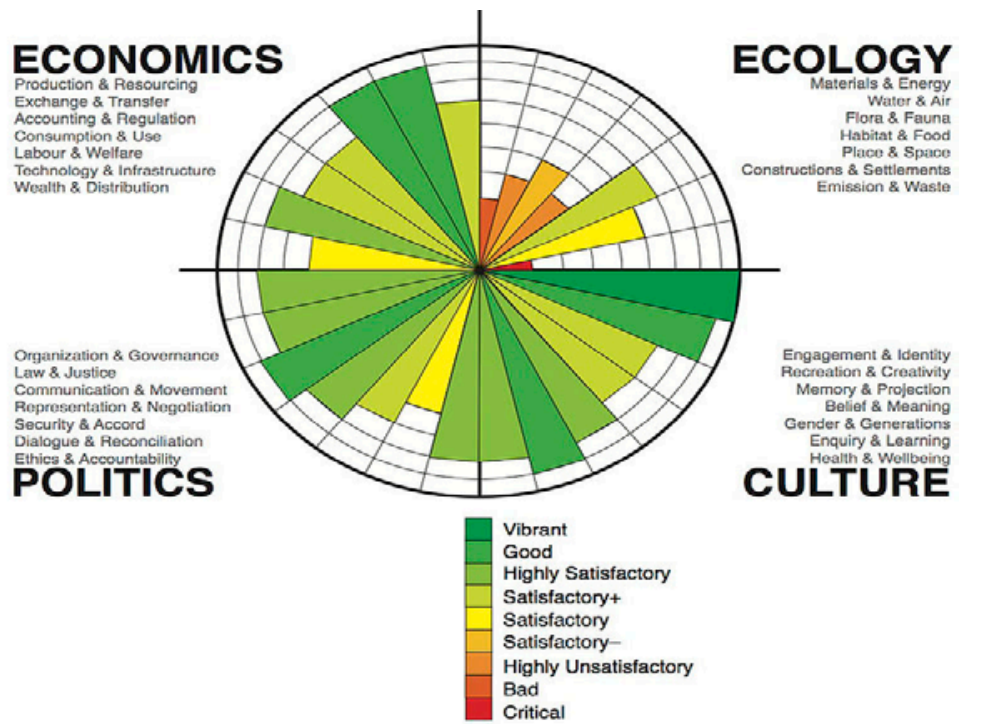

\begin{abstract}
Sustainability
Sustainability has been described in terms of three pillars. In the three-dimensional model, these are seen as "economic, environmental and social" or "ecology, economy and equity". Later a fourth pillar of culture, institutions or governance was included by some authors. Sustainability is all about integration of the four sectors.
\end{abstract}

\section{CIRCLES OF SUSTAINABILITY}

Source: Wikipedia

All these components are to be linked together to attain sustainability. Education is the catalyst which can effectively interlink all of them by bringing improvement in teaching-learning method and providing a good learning environment.

Sustainable Development can be defined as the practice of reserving resources for future generation without any harm to the nature. After Brundtland report Sustainable Development was defined as "the development which meets the need of the present without compromising the ability of the future generations to meet their own needs". Sustainable Development is a process of change in which the exploitation of resources, the direction of investments, the orientation of technological development and institutional changes are all in harmony and enhance both current and future potential to meet human needs and aspirations. It is all about making sure that every individual can enjoy their lives fully in the present as well as in the future. It is based on the principles of normatively, equity, integration and dynamism.

\section{REASONS TO ENGAGE EDUCATION TO SD:}

Primary education provides the base for education at secondary and tertiary level. Historical and contemporary evidence shows that societies that concentrated exclusively on literacy and primary education and ignored Higher Education (e.g Kerala) could not develop - economically, socially or politically. Education at higher level for Sustainable Development is the process of equipping students with knowledge, understanding and skills. It teaches how to live in a way that 
safeguards environmental, social and economic well-being, both in the present and for future. We can consider Education as an institution that is both an ingredient as well as an instrument of Sustainable Development. Reasons for linking Higher Education to SD is quality assurance, employability, accountability and moral obligations.

\section{CHALLENGES:}

(i) Lack of trained professionals in higher educational institutes.

(ii) Lack of inter-disciplinary research.

Collaboration, networking and coordination among different educational institutes.

The truth is that without significant precautions, education can equip people merely to be more effective vandals of the Earth. (Orr, 1994 p5)

\section{PROCESS:}

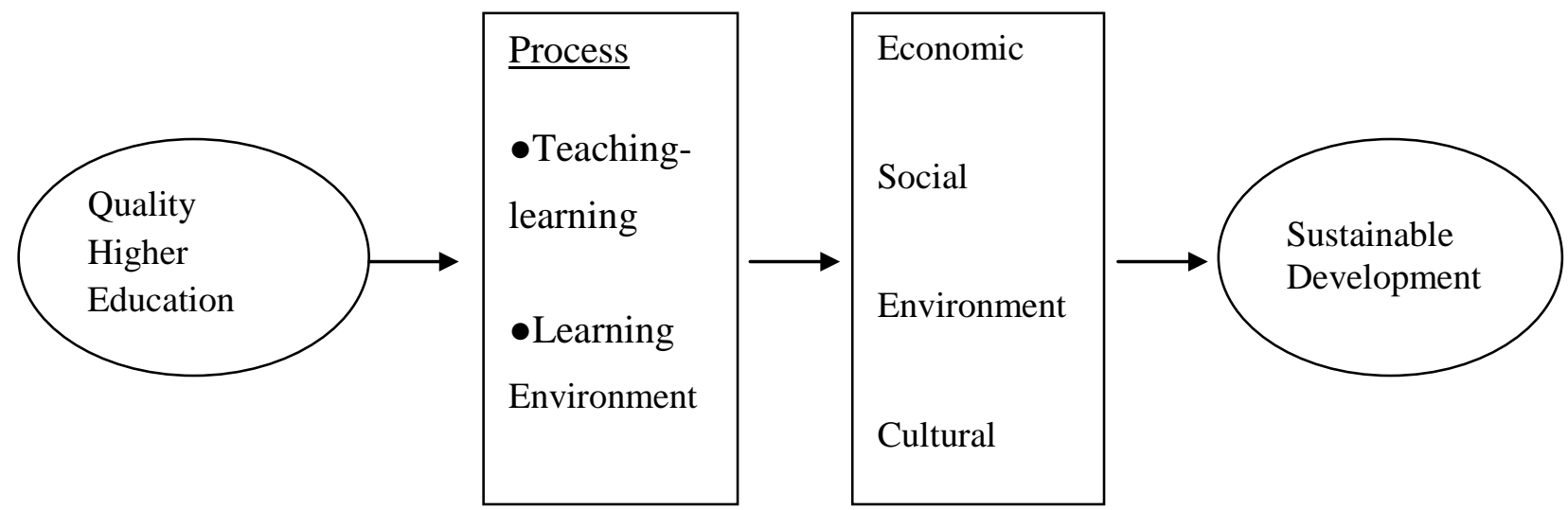

(i) Teaching-Learning Process:

(a) Integrating values \& perceptions of sustainability into personal and professional life.

(b) Empowering people with new knowledge and skills to match with the current market.

(c) To reorient existing educational programmes and to raise awareness.

(d) Motivating scholars to do interdisciplinary research.

Shifts in Teaching and Learning Approaches for Sustainable Development

Transmissive learning

Teacher-centered approach

Individual learning

Emphasis on cognitive objectives only

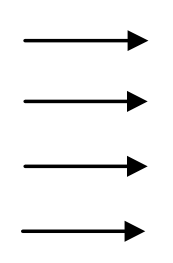

Learning through discovery Learner-centered approach Collaborative learning Cognitive, affective and skills-oriented objectives

(ii) Learning Environment:

The learning environment should be such that:

(a) Making better use of available resources. 


\section{Quality Higher Education: A Need for Sustainable Development}

(b) Modeling good practice to teaching and learning. Experimenting with creative pedagogies this might include using fewer paper resources or developing blended learning approaches.

(d) Awareness of institutional policies, activities and initiatives.

\section{PRESENT SCENARIO IN INDIA:}

(i) Lacks of Awareness-Most students want to obtain degree merely as a preparation for employment. The perception of the usefulness of SD among Science students is far low.

(ii) Most subjects that are able to incorporate the principles of SD within their range of contents are optional.

(iii) Absence of experts with strong background in their disciplines.

(iv) Lack of interdisciplinarity.

(v) Lack of inter connectivity between Universities, Institutions and NGOs to share their information.

\section{RECOMMENDATIONS:}

(i) Access to each and every individual in the society for admission in any institute meant for Higher Education.

(ii) Degree syllabuses should have inconsiderable number of subjects that could incorporate SD perspectives without any requirement for syllabus change.

(iii) Promote interdisciplinarity among areas of knowledge and comprehensive understanding of the main social challenges that requires the collaboration of physical scientists, social scientists, humanities scholars and engineers.

(iv) Learning related to Sustainable Development should principally be incorporated through the use of new teaching methodologies with emphasis upon use of ICT in learning.

(iv) To develop the "Sustainability Literacy Test"- a tool for the various initiatives on sustainability lead by Higher Education Institutes to assess and verify the sustainability literacy of their students when they graduate.

(v) Strict adherence to minimum qualification for appointment of academicians.

(vi) Steps to be taken for specific training for lecturers.

(vii) Support the development of an innovative incentive system for academicians. Their work beyond their discipline to be recognised at various levels.

(ix) Develop regional, national and international networks of academicians engaged in research in the field of sustainability in higher education.

(x) International university networks and partnerships should be developed to promote high quality research and develop internationally competitive curricula and teaching practices and dissemination of innovative.

(xi) In view of dearth of public funds in a rapidly growing economy, Higher Education must be based on public-private partnerships model. 


\section{REFERENCES:}

Castells, Manuel (1994) The University System: Engine of Development in the New World Economy, in Salmi and Verspoor (eds.), pp. 14-40.

Education for Sustainable Development, (ESD). (2011). Leadership Training Course. Announcement, [cited March 30, 2013]. Available from http://jugendlsa.de/weltwaerts/wp content/uploads/2011/02/ESD-Leadership-Training-180211.pdf

Gass, J. R. (1979). Cited in H. Flexner, The curriculum, the disciplines, and interdisciplinarity in higher education: Historical perspective. In J. J. Kockelmans (Ed.), Interdisciplinarity and Higher Education (pp. 93-122). University Park: Pennsylvania State University Press.

Kapur, Devesh, and Pratap Bhanu Mehta. 2004. ”Indian Higher Education Reform: From HalfBaked Socialism to Half-Baked Capitalism.” Harvard University: Center for International Development, Working Paper No. 108. September.

Orr, David W. (1994). Earth in Mind: On Education, Environment, and the Human Prospect. Washington, DC: Island Press.

How to cite this article: H Tripathi (2016), Quality Higher Education: A Need for Sustainable Development, International Journal of Indian Psychology, Volume 3, Issue 3, No. 9, DIP: 18.01.160/20160303, ISBN: 978-1-365-13820-1 